\title{
ANALISIS HARGA SAHAM, VOLUME PERDAGANGAN SAHAM DAN VARIAN RETURN SAHAM TERHADAP BID ASK SPREAD PADA MASA SEBELUM DAN SESUDAH STOCK SPLIT PADA PERUSAHAAN YANG TERDAFTAR DI BEI TAHUN 2011 - 2015
}

\author{
Kevin Immanuel \\ Universitas BundaMulia \\ virecagroup@gmail.com \\ Oktafalia Marisa Muzamil \\ Universitas Bunda Mulia \\ omuzamil@bundamulia.ac.id
}

\begin{abstract}
ABSTRACK
ABSTRACT : The stock split policy is taken by the company to keep stock prices not too high so that its stock can reach many investors and increase stock liquidity. This study also aims to measure whether there is a difference before and after the company does a stock split through bid ask spread. This research method uses event study about market reaction to information from stock split announcement.This type of research includes descriptive research using quantitative data, while data collection techniques consist of library techniques and documentation techniques.

The results showed that the test for normality only trading volume activity (TVA) that qualify and can do paired samples t-test, while the stock price, the variant return and bid ask spread is done by using Wilcoxon test because it does not pass the test of normality. In the paired sample t-test, the results show that there is significant trading activity volume difference before and after stock split. In the Wilcoxon test, the results show that there is no significant price difference before and after stock split, there is no significant difference of return variance before and after stock split, and there is no significant bid ask spread before And after stock splits.

The conclusions can be drawn based on the results of the study that the market conditions are in the bearish market and investors do not provide a quick feedback to the stock split. However, stock splits have increased liquidity from firms due to stock splits to n per sheets and reduced asymmetry costs to be borne by investors. Suggestions from researchers to investors are investors can take advantage of stock split events and must be observant in seeing the stock of a particular company that has prospects, good performance and good reputation in the community. For the company, the company should be wise in determining the ratio for stock prices to be optimal and consider whether the stock market is bearish / bullish market when doing stock split policy.
\end{abstract}

Keywords: stock prices, return, trading volume activity, bid ask spread, and stock split

ABSTRAK : Kebijakan stock split dilakukan perusahaan untuk menjaga harga saham agar tidak terlalu tinggi sehingga sahamnya dapat menjangkau banyak investor dan meningkatkan likuiditas saham. Penelitian ini juga bertujuan untuk mengukur apakah adanya perbedaan sebelum dan sesudah perusahaan melakukan stock split melalui bid ask spread.

Metode penelitian ini menggunakan event study mengenai reaksi pasar terhadap informasi dari pengumuman stock split. Jenis penelitian ini termasuk penelitian deskriptif dengan menggunakan data kuantitatif, sedangkan teknik pengumpulan data terdiri dari teknik pustaka dan teknik dokumentasi.

Hasil penelitian menunjukkan bahwa dalam uji normalitas hanya trading volume activity (TVA) yang lolos dan bisa dilakukan uji paired sample t-test, sedangkan harga saham, varian return dan bid ask spread harus melakukan uji wilcoxon karena tidak lolos uji normalitas. Dalam uji paired sample t-test, hasil menunjukkan bahwa terdapat perbedaan trading volume activity yang signifikan sebelum dan sesudah pemecahan saham. Dalam uji wilcoxon, hasil menunjukkan bahwa tidak terdapat 
perbedaan harga yang signifikan sebelum dan sesudah pemecahan saham (stock split), tidak terdapat perbedaan varian return yang signifikan sebelum dan sesudah pemecahan saham (stock split), dan tidak terdapat perbedaan bid ask spread yang signifikan sebelum dan sesudah pemecahan saham

Kesimpulan yang dapat ditarik berdasarkan hasil penelitian bahwa kondisi pasar berada pada bearish market dan investor tidak memberikan feedback yang cepat terhadap stock split. Namun stock split berhasil meningkat likuiditas dari perusahaan karena pemecahan saham menjadi $\mathrm{n}$ per lembar dan berkurangnya biaya asimetri yang harus ditanggung oleh investor. Saran dari peneliti untuk para investor adalah investor dapat memanfaatkan peristiwa stock split dan harus jeli dalam melihat saham dari perusahaan tertentu yakni yang memiliki prospek, kinerja yang baik dan reputasi yang baik dimata masyarakat. Untuk perusahaan, sebaiknya perusahaan harus bijak dalam menentukan rasio agar harga saham menjadi optimal dan mempertimbangkan kondisi pasar saham apakah bearish / bullish market saat melakukan kebijakan stock split.

Kata kunci : harga saham, varian return, trading volume activity, bid ask spread, stock split

\section{Pendahuluan}

\section{a. Latar belakang}

Tujuan dilakukan pemecahan saham (stock split) adalah untuk menjaga harga agar saham tidak terlalu tinggi sehingga sahamnya lebih memasyarakat dan lebih banyak diperdagangkan. Hal-hal yang perlu diketahui oleh pemegang saham/investor sehubungan dengan pemecahan saham biasanya dari tanggal pengumuman pemecahan saham, dan rasio pemecahan sahamnya sesuai dengan faktor pemecah (split factor).

Didalam pasar modal, investor juga harus memiliki pengetahuan dan informasi tentang bid ask spread untuk membantu investor dalam pengambilan keputusan. Bid ask spread adalah perbedaan harga beli dan jual pada suatu waktu tertentu. Jarak/perbedaan harga beli dan jual itu sering dijadikan indikasi likuiditas pasar. Artinya, jika spread semakin berkurang, maka semakin tinggi likuiditas keadaan pasar saat itu. Salah satu cara juga untuk meningkatkan likuiditas saham adalah dengan melakukan tindakan pemecahan saham (stock split).

Ada beberapa faktor yang diidentifikasi sebagai determinan bid ask spread, yakni harga, volume perdagangan, dan varian return. Harga diidentifikasi berpengaruh negatif terhadap bid ask spread. Harga saham yang senantiasa memberikan return yang tinggi mengindikasikan bahwa saham tersebut disukai oleh investor, sehingga broker/dealer (perantara pedagang efek) tidak perlu memegang saham tersebut terlalu lama sehingga menurunkan biaya pemilikan saham yang berarti mempersempit bid ask spread saham tersebut.Volume perdagangan diidentifikasi berpengaruh terhadap bid ask spread. Volume perdagangan saham yang besar menandakan bahwa saham tersebut aktif ditransaksikan, sehingga broker/dealer tidak perlu menyimpan saham terlalu lama sehingga menurunkan biaya pemilikan saham tersebut yang berdampak pada bid ask spread yang lebih sempit. Varian return dianggap berpengaruh positif terhadap bid ask spread. Pada periode volatilitas harga saham yang tinggi, pedagang berinformasi lebih memiliki peluang untuk memperoleh keuntungan (gain), hal ini menyebabkan broker/dealer memperbesar keuntungan sebagai kompensasi atas resiko kerugian dengan meningkatkan spreadnya. Variabilitas Return saham mewakili risiko yang dihadapi broker/dealer karena memegang suatu saham, semakin besar risiko suatu saham, maka broker/dealer berusaha menutupinya dengan spread yang lebih besar. Jadi terdapat hubungan positif antara varian return saham dengan spread.

Berdasarkan hal tersebut, penulis mengambil keputusan untuk memilih judul penelitian ini adalah "ANALISIS HARGA SAHAM, VOLUME PERDAGANGAN SAHAM DAN VARIAN RETURNSAHAM TERHADAP BID ASK 
SPREAD PADA MASA SEBELUM DAN SESUDAH STOCK SPLIT PADA PERUSAHAAN YANG TERDAFTAR DI BEI TAHUN 2011 - 2015“

\section{b. Identifikasi Masalah}

Berdasarkan latar belakang masalah yang sudah di uraikan sebelumnya, penulis menemukan identifikasi

masalah sebagai berikut :

1. Berlangsungnya fungsi pasar modal (Bruce Lliyd, 1976), adalah meningkatkan dan menghubungkan aliran dana jangka panjang dengan "kriteria pasarnya" secara efisien yang akan menunjang pertumbuhan riil ekonomi secara keseluruhan Sehingga pasar modal menjadi salah satu lembaga yang menunjang lajunya pertumbuhan dan perkembangan perekonomian sebuah negara.

2. Informasi memegang peranan penting terhadap transaksi perdagangan di pasar modal. Informasi juga menjadi kebutuhan mendasar bagi para investor dalam pengambilan keputusan. Pengambilan keputusan ini berkaitan dengan pemilihan investasi yang paling menguntungkan dengan tingkat resiko tertentu.

3. Tindakan pemecahan saham telah menimbulkan efek fatamorgana bagi investor, yaitu investor akan merasa seolaholah menjadi lebih makmur karena memegang saham lebih banyak. Secara teoritis pemecahan saham (stock split) hanya meningkatkan jumlah saham beredar, dan tidak memberikan nilai ekonomis baik bagi perusahaan maupun bagi investor. Jadi, pemecahan saham merupakan tindakan yang tidak memiliki nilai ekonomis.
4. Selain informasi yang harus diketahui para investor, pengetahuan akan bid ask spread juga membantu investor untuk melihat likuidnya perusahaan yang akan ditanamkan, khususnya bagi investor yang mengharapkan capital gain. Bid ask spread adalah perbedaan harga beli dan jual pada suatu waktu tertentu. Jarak/perbedaan harga beli dan jual itu sering dijadikan indikasi likuiditas pasar. Artinya, jika spread semakin berkurang, maka semakin tinggi likuiditas keadaan pasar saat itu. Salah satu cara juga untuk meningkatkan likuiditas saham adalah dengan melakukan tindakan pemecahan saham (stock split).

5. Harga saham dan volume transaksi berpengaruh negatif terhadap bid ask spread, sedangkan varian return berpengaruh positif terhadap bid ask spread.

\section{c. Tujuan dan Manfaat Penelitian}

Sesuai dengan rumusan masalah diatas maka penelitian ini bertujuan antara lain :

1. Untuk mengetahui harga saham berpengaruh signifikan terhadap bid ask spread sebelum pemecahan saham (stock split)

2. Untuk mengetahui volume perdagangan saham berpengaruh signifikan terhadap bid ask spread sebelum pemecahan saham (stock split)

3. Untuk mengetahui varian return saham berpengaruh signikan terhadap bid ask spread sebelum pemecahan saham (stock split) 
4. Untuk mengetahui harga saham berpengaruh signifikan terhadap bid ask spread sesudah pemecahan saham (stock split)

5. Untuk mengetahui volume perdagangan saham berpengaruh signifikan terhadap bid ask spread sesudah pemecahan saham (stock split)

6. Untuk mengetahui varian return saham berpengaruh signifikan terhadap bid ask spread sesudah pemecahan saham (stock split)

7. Untuk mengetahui terdapat perbedaan bid ask spread sebelum dan sesudah perusahaan melakukan pemecahan saham (stock split)

Penelitian ini di harapkan dapat memberi manfaat sebagai berikut :

a. Bagi Perusahaan :

Hasil penelitian yang dilakukan penulis diharapkan dapat memberi manfaat bagi perusahaan yang ingin melakukan pemecahan saham (stock split). Apakah kebijakan dengan melakukan pemecahan saham (stock split) adalah solusi yang tepat bagi perusahaan. Selain itu, perusahaan juga harus mempertimbangkan faktor - faktor dari harga saham, volume perdagangan dan varian return dari saham. Dari faktor faktor tersebut adakah bid ask spreadnya yang dapat memberikan keuntungan baik bagi perusahaan maupun investor.

b. Bagi Investor :

Seperti yang sudah dibahas sebelumnya, informasi akan menjadi sangat penting khususnya bagi investor, diharapkan penelitian yang dilakukan penulis dapat memberikan referensi dan membantu para investor untuk mengambil keputusan dalam menanamkan modalnya didalam suatu perusahaan.

Apakah perusahaan yang melakukan pemecahaan saham (stock split) tersebut memiliki propek di masa yang akan datang, dan nantinya investor dapat mengambil keuntungan dari investasi yang akan dilakukannya tersebut. Untuk itu, investor dapat melihat bid ask spread baik dari harga saham, volume perdagangan saham, dan varian return sebagai acuan dalam mengambil keputusan.

Bagi Penulis :

Hasil penelitian yang dilakukan penulis ini dapat memberikan pengetahuan dan wawasan yang lebih luas mengenai pemecahan saham (stock split) yang dilakukan oleh perusahaan. Disamping itu, penulis mengetahui ada tidaknya pengaruh dari harga saham, volume perdagangan dan varian return saham dari bid ask spread baik sebelum dan sesudah perusahaan melakukan pemecahan saham (stock split).

Bagi Akademis :

Hasil penelitian yang dilakukan penulis, diharapkan dapat memberikan pengetahuan dan wawasan untuk para akademis mengetahui pemecahan saham (stock split). Selain itu penulis mengharapkan penelitian ini dapat menjadi referensi bagi para akademis dan dapat meneruskan penelitian yang dilakukan penulis.

\section{Kajian Pustaka}

\section{Pemecahan Saham ( Stock Split )}

Dalam rangka meningkatkan likuiditas saham emiten, banyak strategi yang dapat dilakukan perusahaan. Salah satunya adalah melakukan stock 
split.Keputusan perusahaan melakukan stock split menggambarkan kondisi perusahaan yang memiliki kinerja perusahaan yang baik. Para investor dan pengamat pada umumnya memiliki pandangan yang positif pada setiap perusahaan yang melakukan stock split, khususnya pandangan secara jangka pendek (Irham Fahmi, 2013:88).

Harga per lembar saham baru setelah stock split adalah sebesar $1 / \mathrm{n}$ dari harga sebelumnya. Dengan demikian, stock split tidak menambah nilai dari perusahaan atau dengan kata lain stock split tidak mempunyai nilai ekonomis, pertanyaannya adalah mengapa perusahaan emiten melakukannya. Kemungkinan alasannya adalah berhubungan dengan likuiditas harga sekuritas dan yang berhubungan dengan sinyal yang akan disampaikan oleh perusahaan ke publik (Jogiyanto, 2013:561-562).

Hal tersebut didukung oleh jurnal " THE EFFECT OF STOCK SPLIT ON ISHARE EXCHANGE - TRADED FUNDS “ yang berisi : Corporations issuing stocks and investment companies trading stocks face the challenge of providing securities that can be purchased by a wide variety of investors who wish to diversify their investment risk. Companies have used stock splits of shares whose price is increasing to attract a broader base of shareholders. We study pre-and postsplit behavior of the measures indicative of the motivations of the investors of these funds and of the brokers selling the funds. We investigate two hypotheses that have been of interest in split literature; broker promotion and trading inconvenience

\section{Tujuan Stock Split}

Tujuan dilakukannya stock split (Irham Fahmi, 2013:89) adalah :

\section{Untuk menghindari harga} saham yang terlalu tinggi sehingga memberatkan publik untuk membeli/memiliki saham tersebut.

2. Mempertahankan tingkat likuiditas saham.

3. Menarik para investor yang berpotensi lebih banyak guna memiliki saham tersebut.

4. Menarik minat investor kecil untuk memiliki saham tersebut, karena jika terlalu mahal maka kepemilikan dana dari investor kecil tidak akan terjangkau.

5. Menambah jumlah saham yang beredar.

6. Memperkecil risiko yang akan terjadi, terutama bagi investor yang ingin memiliki saham tersebut dengan kondisi harga saham yang rendah, maka karena sudah dipecah tersebut artinya telah terjadi diversifikasi investasi.

7. Menerapkan diversifikasi investasi.

\section{Manfaat Stock Split}

Beberapa alasan manajer perusahaan melakukan stock split antara lain (Keown, Scott, Martin, Petty,1996 dalam Rohana, Jeannet, dan Mukhlasin,2003) :

1) Supaya harga saham tidak terlalu mahal sehingga dapat meningkatkan jumlah pemegang saham dan meningkatkan likuiditas saham.

2) Untuk mengembalikan harga dan ukuran perdagangan rata-rata saham kepada kisaran yang telah ditargetkan.

3) Untuk membawa informasi mengenai kesempatan investasi yang berupa peningkatan laba dan dividen kas. 


\section{Teori Bid Ask Spread}

Bid-Ask spread merupakan selisih antara bid price dengan ask price. Bid price adalah harga tertinggi yang dibayarkan oleh seorang pembeli sekuritas tertentu. Sedangkan ask price adalah harga terendah yang bersedia ditawarkan oleh penjual kepada pembeli. Pembeli dan penjual dihubungkan oleh seorang broker yang menerima komisi. Spread adalah perbedaan kurs jual dan kurs beli. Besarnya spread tergantung pada besarnya biaya yang terjadi. Harga permintaan beli (bid price) dan penawaran jual (ask price) merupakan fungsi dari kos dan informasi yang dimiliki dealer.

\section{Pengaruh Harga Saham terhadap} Bid Ask Spread

Harga saham. Harga saham dapat didefinisikan sebagai harga pasar. Harga pasar menjadi harga yang paling mudah untuk ditentukan, karena harga saham yang sedang berlangsung. Jika pasar bursa sudah tutup, maka harga pasar adalah harga penutupnya (closing price). Jadi harga pasar inilah yang menyatakan naik turunnya suatu saham (Ang, 1997). Kebanyakan orang menginginkan untuk membeli harga saham yang terjangkau, sehingga harga saham yang cenderung tinggi kurang dilirik oleh kebanyakan orang.

\section{Pengaruh Volume Perdagangan terhadap Bid Ask Spread \\ Volume perdagangan. Volume} perdagangan merupakan jumlah transaksi yang diperdagangkan pada waktu tertentu. Volume diperlukan untuk menggerakan harga saham (Sumiyana, 2007). Volume perdagangan saham merupakan aktivitas transaksi perdagangan suatu saham atau volume saham yang diperdagangkan pada periode $\mathrm{t}$ (Wibowo, 2005).

Pengaruh Varian Return Saham terhadap Bid Ask Spread

Varians return. Varian return menunjukkan variabilitas return di seputar return normal yang di akibatkan adanya volatilitas/fluktuasi harga (Ady et al.2010:231). Varians return dalam hal ini mewakili risiko saham yang di sinyalir dapat mempengaruhi besar kecilnya bid ask spread saham. Varian return saham mewakili risiko saham yang dihadapi oleh dealer.

Tabel 1:Penelitian

Terdahulu

\begin{tabular}{|c|c|c|c|}
\hline No & Peneliti & $\begin{array}{c}\text { Tahu } \\
n\end{array}$ & Hasil \\
\hline 1 & $\begin{array}{l}\text { M. } \\
\text { Taufiq } \\
\text { Noor } \\
\text { Rokhma } \\
\text { n }\end{array}$ & 2009 & 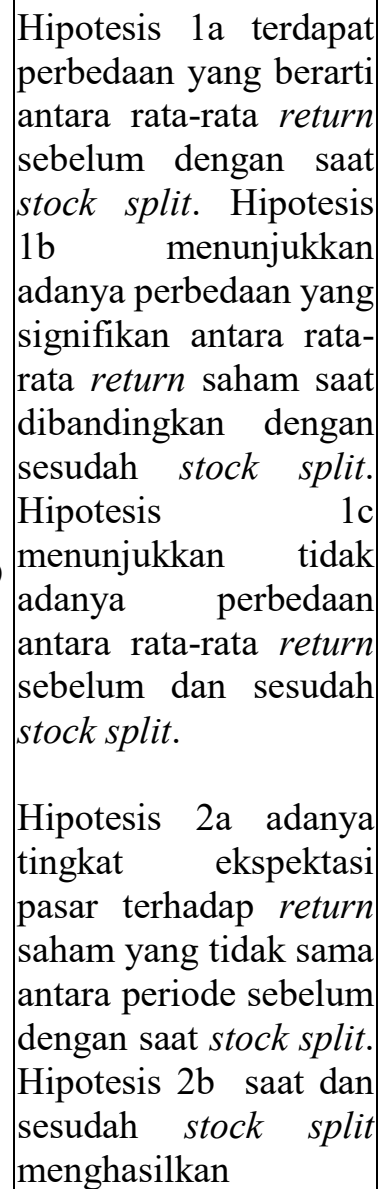 \\
\hline
\end{tabular}




\begin{tabular}{|c|c|c|c|}
\hline & & & 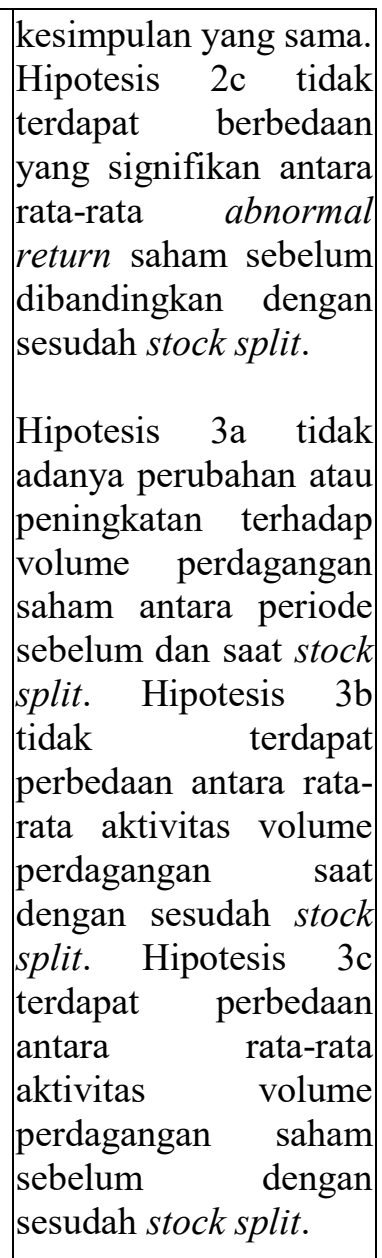 \\
\hline 2 & $\begin{array}{l}\text { Febri } \\
\text { Nova } \\
\text { Indah }\end{array}$ & 2015 & 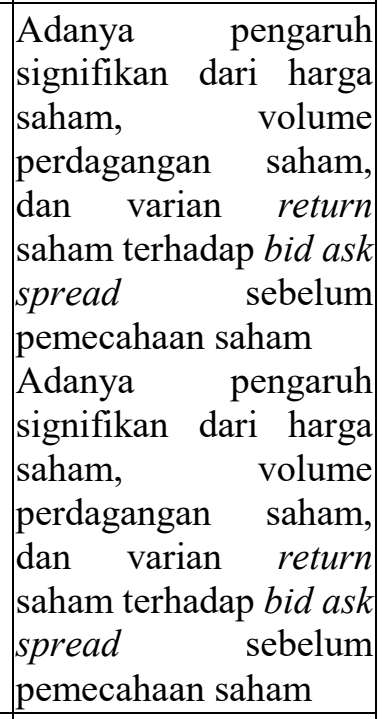 \\
\hline 3 & $\begin{array}{l}\text { Iin } \\
\text { Indarti }\end{array}$ & 2011 & $\begin{array}{l}\text { Terdapat perbedaan } \\
\text { rata-rata harga saham } \\
\text { yang signifikan pada } \\
\text { periode sebelum dan } \\
\text { sesudah pengumuman } \\
\text { pemecahan saham. }\end{array}$ \\
\hline
\end{tabular}

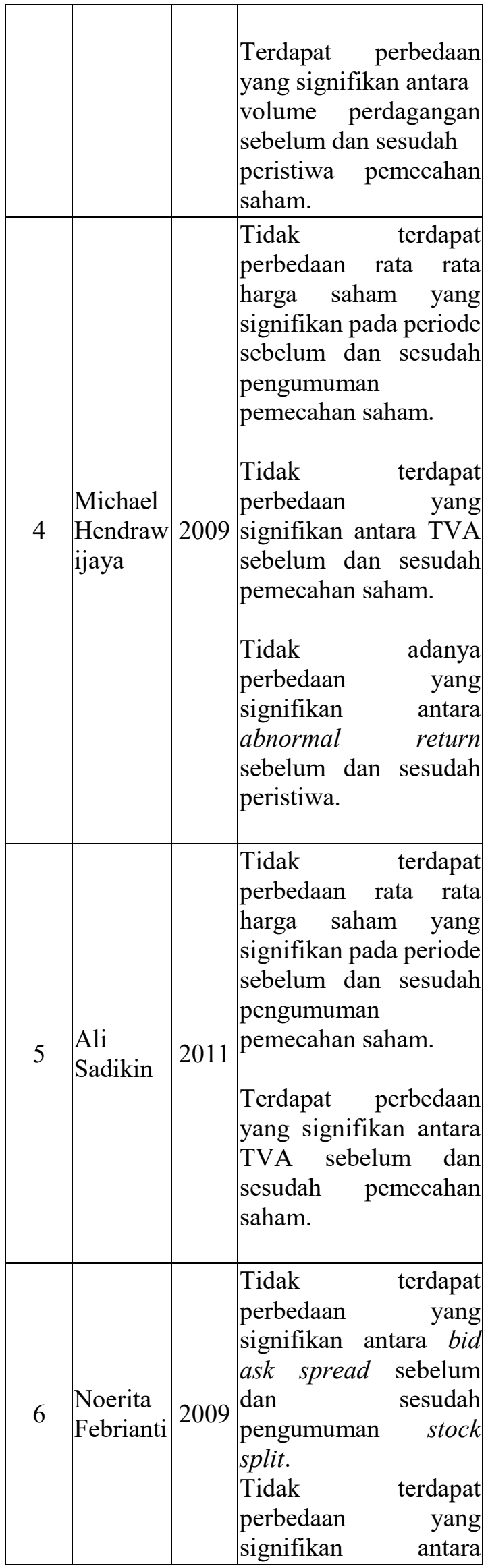




\begin{tabular}{|l|l|lr|}
\hline & & $\begin{array}{l}\text { volatilitas saham } \\
\text { sebelum dan sesudah } \\
\text { pengumuman } \\
\text { split. }\end{array}$ \\
\hline
\end{tabular}

Sumber (di susun peneliti, 2017)

\section{METODE PENELITIAN}

\section{Gambaran Umum Subyek dan Obyek Penelitian}

Subyek Penelitian. Subyek penelitian menurut Arikunto (2007:152) merupakan sesuatu yang sangat penting kedudukannya didalam penelitian, subyek penelitian harus ditata sebelum penelitian siap untuk mengumpulkan data. Subyek penelitian dapat berupa benda, hal atau manusia. Namun dalam subyek penelitian yang dilakukan penulis terpusat pada perusahaan yang terdaftar di Bursa Efek Indonesia (BEI) yang melakukan pemecahan saham atau stock split.

Obyek Penelitian. Obyek penelitian adalah suatu atribut atau sifat atau nilai dari orang, obyek atau kegiatan yang mempunyai variasi tertentu yang ditetapkan oleh peneliti untuk dipelajari dan kemudian ditarik kesimpulannya (Sugiyono,2012), sehingga obyek dalam penelitian adalah reaksi pasar/investor terhadap peristiwa pemecahan saham (stock split). Hal tersebut dilihat dari bid ask spread baik sebelum dan sesudah perusahaan melakukan pemecahan saham (stock split). Adapun variabelvariabel yang digunakan untuk mengukur bid ask spread yakni harga saham, volume perdagangan saham, dan varian return saham.

\section{Jenis Penelitian}

Jenis penelitian yang digunakan dalam penelitian ini adalah jenis penelitian deskriptif dengan data-data kuantitatif. Karena dalam penelitian ini sangat membutuhkan data berupa angka dan penelitian ini diteliti menggunakan analisis statistik. Metode kuantitatif dapat diartikan sebagai metode penelitian yang berlandaskan pada filsafat positivisme, digunakan untuk meneliti pada populasi atau sampel tertentu, pengumpulan data menggunakan instrumen penelitian, analisis data bersifat kuantitatis atau statistik, dengan tujuan untuk menguji hipotesis yang telah ditetapkan (Sugiyono, 2012).

Namun penelitian ini juga tidak lepas dari metodologi studi peristiwa (event study). Studi peristiwa (event study) merupakan studi yang mempelajari reaksi pasar terhadap suatu peristiwa (event) yang informasinya dipublikasikan melalui pengumuman (Hartono, 2013). Peristiwa yang dimaksud dalam penelitian ini adalah pengumuman dimana perusahaan akan melakukan pemecahan saham (stock split) dalam Bursa Efek Indonesia pada periode 2011-2015. Jangka waktu yang digunakan pada penelitian ini adalah 5 hari sebelum dan sesudah perusahaan melakukan pemecahan saham (stock split)

\section{Jenis dan Sumber Data}

Peneliti lebih mengutamakan data time series, karena data time series atau data deret waktu adalah sekumpulan data dari suatu fenomena tertentu yang didapat dalam beberapa interval waktu tertentu, misalnya dalam waktu mingguan, bulanan, atau tahunan. Berikut data sekunder dalam penelitian ini :

1. Perusahaan yang terdaftar di BEI dan melakukan pemecahaan saham selama periode 2011 - 2015.

2. Selain itu data lain yang dibutuhkan mulai dari ; harga saham, volume perdagangan, varian return saham didalam bid dan ask spread sebelum dan sesudah pemecahan saham (stock split).

\section{Populasi dan Sampel}


Menurut Sabar (2007) populasi adalah keseluruhan subyek penelitian. Apabila seseorang ingin meneliti semua elemen yang ada dalam wilayah penelitian, maka penelitiannya merupakan penelitian populasi atau studi populasi atau studi sensus. Sedangkan menurut
Sugiyono (2011:80) pengertian populasi adalah wilayah generalisasi yang terdiri atas: obyek/subyek yang mempunyai kualitas dan karakteristik tertentu yang ditetapkan oleh peneliti untuk dipelajari dan kemudian ditarik kesimpulannya.

Tabel 2: Sampel

\begin{tabular}{|c|c|c|c|c|}
\hline No & Kode & Nama Perusahaan & Rasio & $\begin{array}{c}\text { Tanggal Stock } \\
\text { Split }\end{array}$ \\
\hline
\end{tabular}

\begin{tabular}{|c|c|c|c|c|}
\hline 1 & BBRI & Bank Rakyat Indonesia (Persero) Tbk. & $1: 2$ & 14-Jan-11 \\
\hline 2 & LSIP & PP London Sumatra Indonesia Tbk. & $1: 5$ & $25-F e b-11$ \\
\hline 3 & BTPN & $\begin{array}{l}\text { Bank Tabungan Pensiunan Nasional } \\
\text { Tbk. }\end{array}$ & $1: 5$ & 28-Mar-11 \\
\hline 4 & INTA & Intraco Penta Tbk. & $1: 5$ & 6-Jun-11 \\
\hline 5 & PBRX & Pan Brothers Tbk. & $1: 4$ & 15-Jun-11 \\
\hline 6 & MAIN & Malindo Feedmill Tbk. & $1: 5$ & 15-Jun-11 \\
\hline 7 & AUTO & Astra Otoparts Tbk. & $1: 5$ & 24-Jun-11 \\
\hline 8 & SSIA & Surya Semesta Internusa Tbk & $1: 4$ & 7-Jul-11 \\
\hline 9 & MTFN & Capitalinc Investment Tbk & $1: 5$ & 11-Jul-11 \\
\hline 10 & JTPE & Jasuindo Tiga Perkasa Tbk. & $1: 5$ & 26-Jul-11 \\
\hline 11 & PTRO & Petrose Tbk. & $1: 10$ & 6-Mar-12 \\
\hline 12 & PWON & Pakuwon Jati Tbk. & $1: 4$ & 30-Mar-12 \\
\hline 13 & ASII & Astra International Tbk. & $1: 10$ & 5-Jun-12 \\
\hline 14 & IMAS & Indomobil Sukses Internasional Tbk. & $1: 2$ & 7-Jun-12 \\
\hline 15 & MDRN & Modern Internasional Tbk. & $1: 5$ & 6-Jul-12 \\
\hline 16 & DKFT & Central Omega Resources Tbk. & $1: 5$ & 3-Aug-12 \\
\hline 17 & KREN & Kresna Graha Sekurindo Tbk. & $1: 4$ & 7-Aug-12 \\
\hline 18 & IDKM & Indosiar Karya Media Tbk. & $1: 5$ & 3-Oct-12 \\
\hline 19 & KLBF & Kalbe Farma Tbk. & $1: 5$ & 8-Oct-12 \\
\hline 20 & SCMA & Surya Citra Media Tbk. & $1: 5$ & 29-Oct-12 \\
\hline 21 & ACES & Ace Hardware Tbk. & $1: 10$ & 1-Nov-12 \\
\hline 22 & BRNA & Berlina Tbk. & $1: 5$ & 6-Nov-12 \\
\hline 23 & JPFA & Japfa Comfeed Indonesia Tbk. & $1: 5$ & 19-Apr-13 \\
\hline 24 & ARNA & Arwana Citramulia Tbk. & $1: 4$ & 8-Jul-13 \\
\hline 25 & AMRT & Sumber Alfaria Trijaya Tbk. & $1: 10$ & 29-Jul-13 \\
\hline 26 & TLKM & Telekomunikasi Indonesia Tbk. & $1: 5$ & 28-Aug-13 \\
\hline 27 & MDLN & Modernland Realty Tbk. & $1: 2$ & 13-Nov-13 \\
\hline 28 & ROTI & Nippon Indosari Corpindo Tbk. & $1: 5$ & 29-Nov-13 \\
\hline 29 & CMPP & Centris Multi Persada Pratama Tbk. & $1: 4$ & 3-Sep-14 \\
\hline 30 & LTLS & Lautan Luas Tbk. & $1: 2$ & 9-Jan-15 \\
\hline
\end{tabular}




\begin{tabular}{|l|l|l|l|l|}
\hline 31 & LEAD & Logindo Samudramakmur Tbk. & $1: 4$ & 19 -May-15 \\
\hline 32 & MIKA & Mitra Keluarga Karyasehat Tbk. & $1: 10$ & 16 -Oct-15 \\
\hline 33 & DSNG & Dharma Satya Nusantara Tbk. & $1: 5$ & 19 -Oct-15 \\
\hline
\end{tabular}

Sumber (di susun peneliti, 2017)

\section{Uji Paired Sample t-Test}

Uji paired sample t-test atau uji t sampel berpasangan digunakan untuk menganalisis dan menguji perbedaan rata-rata dari dua kelompok sampel yang berpasangan atau berhubungan (Priyatno, 2012).

\section{Uji Wilcoxon}

Menurut Santoso (2015 : 3) jika jumlah data yang digunakan merupakan sampel kecil atau jumlah data kurang dari 30 dan tidak berdistribusi secara normal maka metode penelitian yang digunakan adalah metode statistik nonparametrik. Untuk uji dua sampel berpasangan didalam statistik nonparametrik menggunakan uji wilcoxon.

\section{Hasil dan Pembahasan}

Uji Paired Sample T Test

TVA (Trading Volume Activity)

Tabel 3: Paired Samples Correlations

\begin{tabular}{|lr|r|r|r|}
\hline & \multicolumn{1}{|c|}{ Correlation } & Sig. \\
\hline Pair 1 & TVA Sebelum \& TVA Sesudah & 33 &, 913 &, 000 \\
\hline
\end{tabular}
Sumber : Hasil Olah Data SPSS 21

Tabel 4: Paired Samples Test

\begin{tabular}{|c|c|c|c|c|c|c|c|c|c|}
\hline & \multicolumn{5}{|c|}{ Paired Differences } & \multirow[t]{3}{*}{$\mathrm{T}$} & \multirow[t]{3}{*}{$\mathrm{df}$} & \multirow{3}{*}{$\begin{array}{l}\text { Sig. } \\
\text { (2- } \\
\text { tailed) }\end{array}$} \\
\hline & & \multirow[t]{2}{*}{ Mean } & \multirow[t]{2}{*}{$\begin{array}{c}\text { Std. } \\
\text { Deviation }\end{array}$} & \multirow[t]{2}{*}{$\begin{array}{l}\text { Std. Error } \\
\text { Mean }\end{array}$} & \multicolumn{2}{|c|}{$\begin{array}{c}95 \% \\
\text { Confidence } \\
\text { Interval of the } \\
\text { Difference }\end{array}$} & & & \\
\hline & & & & & Lower & Upper & & & \\
\hline Pair 1 & $\begin{array}{l}\text { TVA Sebelum } \\
\text { TVA Sesudah }\end{array}$ & $\begin{array}{r}, 00114 \\
1214\end{array}$ & ,001007 &, 0001754 & $\begin{array}{r}- \\
, 0014 \\
985\end{array}$ &, 00078 & $-6,505$ & 32 &, 000 \\
\hline
\end{tabular}

Sumber : Hasil Olah Data SPSS 21

Berdasarkan tabel diatas diketahui bahwa nilai sgnifikansi (2-tailed) yang dihasilkan pada uji paired samples $t$ test adalah sebesar 0,000 , atau $\alpha(0,05)>$ sig $(0,000)$. Berdasarkan hasil tersebut, maka keputusannya adalah Ho ditolak yang artinya terdapat perbedaan Trading Volume Activity (TVA) yang signifikan antara sebelum dan sesudah pemecahan saham (stock split).Berdasarkan sampel yang telah didapatkan, rasio yang dilakukan perusahaan berkisar antara 1:2, $1: 4,1: 5$, dan $1: 10$.

Selain itu, hasil tersebut mencerminkan bahwa kebijakan stock split yang dilakukan oleh perusahaan telah mendapat reaksi dari pasar yang positif. Kenaikan yang terjadi pada volume perdagangan tersebut adalah cerminan dari kenaikan aktivitas jual beli para investor dibursa. Dengan perdagangan suatu saham yang aktif dengan volume 
perdagangan yang meningkat menunjukkan bahwa saham dari emiten yang melakukan kebijakan stock split tersebut disukai oleh para investor sehingga saham tersebut akan cepat diperdagangkan dan mempengaruhi likuiditas dari saham tersebut.Hasil tersebut juga mendukung penelitian yang dilakukan oleh Iin Indarti (2011) yaitu stock split yang dilakukan perusaahan dapat memberikan perbedaan yang signifikan pada Trading Volume Activity (TVA) antara sebelum dan sesudah pemecahan saham (stock split).

\section{Uji Wilcoxon}

\section{Harga Saham}

Tabel 5: Ranks

\begin{tabular}{|ll|r|r|r|}
\hline & N & Mean \\
& Rank & Sum of Ranks \\
\hline & Negative Ranks & $16^{\mathrm{a}}$ & 13,88 & 222,00 \\
Harga Sesudah & Positive Ranks & $17^{\mathrm{b}}$ & 19,94 & 339,00 \\
Harga Sebelum & Ties & $0^{\mathrm{c}}$ & & \\
& Total & 33 & & \\
\hline
\end{tabular}

Test Statistics ${ }^{a}$

\begin{tabular}{|l|r|}
\hline & \multicolumn{2}{|c|}{$\begin{array}{c}\text { Harga Sesudah - } \\
\text { Harga Sebelum }\end{array}$} \\
\hline $\begin{array}{l}\text { Z } \\
\text { Asymp. Sig. } \\
\text { (2-tailed) }\end{array}$ & $-1,045^{\mathrm{b}}$ \\
\hline
\end{tabular}

a. Wilcoxon Signed Ranks Test

b. Based on negative ranks.

Sumber : Hasil Olah Data SPSS 21

Berdasarkan tabel diatas diketahui bahwa nilai signifikansi (2-tailed) yang dihasilkan pada uji wilcoxon adalah sebesar 0,296 , atau $\alpha(0,05) \leq \operatorname{sig}(0,296)$. Berdasarkan hasil tersebut, maka keputusannya adalah Ho tidak ditolak. Artinya tidak terdapat perbedaan harga yang signifikan antara sebelum dan sesudah pemecahan saham (stock split). Penulis melihat dari sisi IHSG (Indeks Harga Saham Gabungan) sesuai tahun penelitian yakni 2011-2015. IHSG merupakan indeks dari seluruh saham yang diperdagangkan dalam BEI, sehingga dapat menjadi acuan bagi indikator pergerakan saham yang ada di dalam BEI.

Penulis melihat bahwa rata-rata IHSG pada tahun 2014 adalah yang tertinggi kemudian diikuti tahun 2015, 2013,

2012, 2011. Sedangkan apabila dilihat dari sampel yang ada pada penelitian ini, dimana pada tahun 2011 ada 10 emiten, tahun 2012 ada 12 emiten, tahun 2013 ada 6 emiten, tahun 2014 ada 1 emiten dan 2015 ada 4 emiten. Dari sampel tersebut sangat didominasi oleh tahun 2011 dan 2012, padahal rata-rata IHSG saat tahun tersebut cenderung lebih rendah daripada tahun-tahun berikutnya.

Apabila rata-rata IHSG cenderung turun atau rendah, maka rata-rata harga saham yang diperdagangkan oleh BEI tersebut juga mengalami penurunan. Sehingga penulis melihat bahwa banyak perusahaan yang melakukan kebijakan stock split saat kondisi IHSG sedang rendah (bearish) untuk memberikan ketertarikan bagi para investor agar bisa 
memiliki saham dari perusahaan yang melakukan kebijakan stock split.

Hasil penelitian menunjukkan tidak terdapat perbedaan harga yang signifikan antara sebelum dan sesudah pemecahan saham (stock split). Secara statistik, diperoleh kesimpulan bahwa perbedaan antara rata-rata harga saham sebelum pemecahan saham dengan sesudah pemecahan saham adalah tidak signifikan. Rata-rata harga sebelum pemecahan saham sebesar Rp. $1.611,7470$ sedangkan rata-rata harga sesudah pemecahan saham sebesar Rp. $1.641,5515$.

Dari segi teoritis, yaitu ditinjau dari trading range theory, yang menyatakan bahwa dengan melakukan pemecahan saham, harga saham yang terlalu tinggi, yang menyebabkan saham tersebut menjadi kurang aktif diperdagangkan, akan menjadi lebih likuid setelah pengumuman pemecahan saham sehingga akan semakin banyak investor yang mampu bertransaksi, tidak terjadi dalam penelitian ini. Hasil penelitian justru membuktikan bahwa tidak ada perbedaan harga saham yang signifkan pada periode 5 hari sebelum pengumuman pemecahan saham dan periode 5 hari sesudah pengumuman pemecahan saham.

Perbedaan harga saham yang tidak signifikan pada periode sebelum sesudah pengumuman pemecahan saham, menunjukkan bahwa investor di Indonesia tidak memberikan feedback yang cepat terhadap informasi yang diterimanya. atau investor menganggap bahwa peristiwa pemecahan saham bukanlah good news, sehingga tidak terjadi perbedaan harga saham yang signifikan pada periode sebelum dan sesudah pemecahan saham.

Hasil penelitian ini juga mendukung penelitian yang dilakukan oleh Michael Hendrawijaya (2009) yang menunjukkan hasil penelitian juga tidak terdapat perbedaan yang signifikan sebelum dan sesudah pemecahan saham (stock split).

\section{Varian Return}

Tabel 6: Ranks Varian Return

\begin{tabular}{|ll|r|c|c|}
\hline & N & $\begin{array}{c}\text { Mean } \\
\text { Rank }\end{array}$ & $\begin{array}{c}\text { Sum of } \\
\text { Ranks }\end{array}$ \\
\hline & Negative Ranks & $12^{\mathrm{a}}$ & 15,00 & 180,00 \\
Varian Return Sesudah & Positive Ranks & $21^{\mathrm{b}}$ & 18,14 & 381,00 \\
Varian Return Sebelum & Ties & & \\
& Total & 33 & & \\
\hline
\end{tabular}

a. Varian Return Sesudah $<$ Varian Return Sebelum

b. Varian Return Sesudah $>$ Varian Return Sebelum

c. Varian Return Sesudah $=$ Varian Return Sebelum

Test Statistics ${ }^{\mathrm{a}}$

\begin{tabular}{|l|r|}
\hline & \multicolumn{1}{|c|}{$\begin{array}{l}\text { Varian Return } \\
\text { Sesudah - Varian } \\
\text { Return Sebelum }\end{array}$} \\
\hline$Z$ & $-1,796^{\text {b }}$ \\
$\begin{array}{l}\text { Asymp. Sig. (2- } \\
\text { tailed) }\end{array}$ &, 073 \\
\hline
\end{tabular}

a. Wilcoxon Signed Ranks Test

b. Based on negative ranks.

Sumber : Hasil Olah Data SPSS 21 
Berdasarkan tabel diatas diketahui bahwa nilai signifikansi (2-tailed) yang dihasilkan pada uji wilcoxon adalah sebesar 0,073, atau $\alpha(0,05) \leq \operatorname{sig}(0,073)$. Berdasarkan hasil tersebut, maka keputusannya adalah Ho tidak ditolak. Artinya tidak terdapat perbedaan varian return saham yang signifikan antara sebelum dan sesudah pemecahan saham (stock split).

Berdasarkan hasil penelitian yang terjadi pada harga, dimana tidak terdapat perbedaan harga yang signifikan antara sebelum dan sesudah melakukan stock split, Hal ini tersebut diakibatkan karena investor tidak mengantisipasi adanya informasi baru yang dipublikasikan ke pasar, atau investor menganggap bahwa peristiwa pemecahan saham bukanlah good news, dan bukanlah sinyal yang baik dalam memperoleh keuntungannya sehingga tidak mengubah preferensi investor terhadap keputusan investasinya.

Lalu peristiwa pemecahan saham (stock split) juga tidak membawa kandungankandungan informasi / signalling tentang akan adanya keuntungan yang bisa diperoleh dimasa mendatang. Hasil penelitian ini relevan dengan penelitian yang dilakukan Michael Hendrawijaya (2009) menunjukkan tidak terdapat perbedaan harga yang signifikan antara sebelum dan sesudah pemecahan saham (stock split).

\section{Bid Ask Spread}

Tabel 7: Ranks Bid Ask Spread

\begin{tabular}{|c|c|c|c|c|}
\hline & & $\mathrm{N}$ & $\begin{array}{l}\text { Mean } \\
\text { Rank }\end{array}$ & $\begin{array}{l}\text { Sum of } \\
\text { Ranks }\end{array}$ \\
\hline \multirow{4}{*}{$\begin{array}{l}\text { Bid Ask Spread Sesudah } \\
\text { Bid Ask Spread Sebelum }\end{array}$} & $\begin{array}{l}\text { Negative } \\
\text { Ranks }\end{array}$ & $15^{a}$ & 17,27 & 259,00 \\
\hline & $\begin{array}{l}\text { Positive } \\
\text { Ranks }\end{array}$ & $18^{b}$ & 16,78 & 302,00 \\
\hline & Ties & $0^{c}$ & & \\
\hline & Total & 33 & & \\
\hline
\end{tabular}
a. Bid Ask Spread Sesudah < Bid Ask Spread Sebelum
b. Bid Ask Spread Sesudah > Bid Ask Spread Sebelum
c. Bid Ask Spread Sesudah = Bid Ask Spread Sebelum

Test Statistics ${ }^{a}$

\begin{tabular}{|l|r|}
\hline & \multicolumn{1}{|c|}{$\begin{array}{c}\text { Bid Ask Spread } \\
\text { Sesudah - Bid Ask } \\
\text { Spread Sebelum }\end{array}$} \\
\hline Z &,$- 384^{\mathrm{b}}$ \\
Asymp. Sig. (2- \\
tailed)
\end{tabular}

a. Wilcoxon Signed Ranks Test

b. Based on negative ranks.

Sumber : Hasil Olah Data SPSS 21

Berdasarkan tabel diatas diketahui bahwa nilai signifikansi (2-tailed) yang dihasilkan pada uji

wilcoxon adalah sebesar 0,701 , atau $\alpha$ $(0,05) \leq \operatorname{sig}(0,701)$. Berdasarkan hasil tersebut, maka keputusannya adalah Ho tidak ditolak. Artinya tidak terdapat perbedaan bid ask spread yang signifikan 
antara sebelum dan sesudah pemecahan saham (stock split).

Berdasarkan hasil penelitian tentang harga saham, dan trading volume activity (TVA) berkaitan dengan hasil bid ask spread yang diteliti tersebut. Dimana hasil sebelumnya mengatakan tidak adanya perbedaan yang signifikan tentang harga sebelum dan sesudah melakukan stock split, namun terdapat perbedaan signifikan pada TVA sebelum dan sesudah melakukan stock split. Hal tersebut mengakibatkan penurunan biaya kepemilikan saham yang ditanggung trader sehingga dapat mempersempit spread dari saham tersebut dan membuat saham menjadi likuid.

Hasil penelitian ini mendukung penelitian sebelumnya yang dilakukan oleh Noerita Febrianti (2014) yang menyatakan bahwa tidak terdapat perbedaan bid ask spreadyang signifikan antara sebelum dan sesudah pemecahan saham (stock split) dimana rata-rata bid ask spread yang terjadi sesudah pengumuman stock split lebih rendah jika dibandingkan dengan sebelum adanya pengumuman stock split. Hal ini terjadi karena adverse information cost (biaya asimetri informasi) dan inventory holding cost (biaya kepemilikan saham) sebagai komponen dari bid ask spread semakin kecil akibat adanya peristiwa stock split.

Informasi stock split yang diumumkan oleh emiten akan cepat diketahui oleh pelaku pasar termasuk para investor sehingga mengurangi biaya asimetri informasi yang harus ditanggung oleh investor. Peristiwa stock split yang mengandung sinyal tentang peningkatan return yang akan diperoleh investor mengakibatkan perdagangan saham semakin aktif.

Mengetahui hal tersebut para pemegang saham tidak akan menyimpan saham yang dimilikinya dalam jangka waktu yang lama dengan tujuan untuk mendapatkan capital gain sehingga biaya kepemilikan saham juga akan berkurang. Rata-rata bid ask spread yang lebih rendah sesudah stock split mengindikasikan bahwa tujuan perusahaan dalam melakukan stock split untuk meningkatkan likuiditasnya tercapai.

Hasil tersebut mengindikasikan bahwa pada hari kelima sebelum pengumuman stock split investor belum mendengar informasi bahwa akan terjadi peristiwa stock split sehingga tidak terdapat reaksi pasar yang ditunjukkan oleh tidak adanya perbedaan pada pasangan hari kelima sebelum dan sesudah stock split atau investor yang sudah mengetahui informasi tentang stock split tidak memberikan reaksi yang positif sehingga tidak terjadi perbedaan pada bid ask spread tersebut

\section{Simpulan dan Saran}

Berdasarkan hasil penelitian yang dilakukan oleh penulis terkait perbedaan harga saham, varian return, trading volume activity (TVA) dan bid ask spread pada masa sebelum dan sesudah kebijakan stock split yang dilakukan oleh perusahaan, maka penulis menarik beberapa kesimpulan.

Adapun kesimpulan dalam penelitian ini adalah sebagai berikut :

1. Tidak terdapat perbedaan harga yang signifikan antara sebelum dan sesudah pemecahan saham (stock split). Penulis melihat dari sisi IHSG (Indeks Harga Saham Gabungan) dimana saat periode 2011-2015 saat itu kondisi pasar tidak begitu bagus (bearish), dan investor di Indonesia juga tidak memberikan feedback yang cepat terhadap informasi yang diterimanya. atau investor menganggap bahwa peristiwa pemecahan saham bukanlah good news,

2. Tidak terdapat perbedaan varian return saham yang signifikan antara sebelum dan sesudah pemecahan saham (stock split). Hal ini tersebut diakibatkan dari hasil penelitian tidak terdapat perbedaan harga yang signifikan antara sebelum dan 
sesudah pemecahan saham (stock split) yang membuat para investor tidak mengantisipasi adanya informasi baru yang dipublikasikan ke pasar.

Selain itu, investor juga menganggap bahwa peristiwa pemecahan saham bukanlah good news, dan bukanlah sinyal yang baik dalam memperoleh keuntungannya sehingga tidak mengubah preferensi investor terhadap keputusan investasinya.

3. Terdapat perbedaan Trading Volume Activity (TVA) yang signifikan antara sebelum dan sesudah pemecahan saham (stock split). Perusahaan menginginkan agar masyarakat umum terutama investor agar dapat memiliki saham dari perusahaan tersebut sehingga harga saham dipecah menjadi $\mathrm{n}$ per lembar.

Dengan perdagangan suatu saham yang aktif dengan volume perdagangan yang meningkat menunjukkan bahwa saham dari emiten yang melakukan kebijakan stock split tersebut disukai oleh para investor sehingga saham tersebut akan cepat diperdagangkan dan mempengaruhi likuiditas dari saham tersebut.

4. Tidak terdapat perbedaan bid ask spread yang signifikan antara sebelum dan sesudah pemecahan saham (stock split). Hal ini terjadi karena adverse information cost (biaya asimetri informasi) dan inventory holding cost (biaya kepemilikan saham) sebagai komponen dari bid ask spread semakin kecil akibat adanya peristiwa stock split. Informasi stock split akan mendapat reaksi dari para investor sehingga mengurangi biaya asimetri informasi yang harus ditanggung oleh investor.
Peristiwa stock split yang mengandung sinyal tentang peningkatan return yang akan diperoleh investor mengakibatkan perdagangan saham semakin aktif dan mengindikasikan bahwa tujuan perusahaan dalam melakukan stock split untuk meningkatkan likuiditasnya tercapai.

\section{Saran}

Setelah memberikan kesimpulan dari hasil penelitian yang telah diperoleh oleh penulis. Penulis juga akan memberikan beberapa saran terkait oleh penelitian yang dilakukan penulis sebagai berikut :

Bagi investor :

1. Investor dapat memanfaatkan peristiwa stock split yang dilakukan perusahaan. Jika harga saham dari suatu emiten sudah terlalu tinggi, maka investor tidak bisa memiliki saham tersebut. Namun dengan kebijakan stock split, memungkinkan investor dapat memiliki saham dari emiten tersebut.

2. Walaupun investor dapat memanfaatkan peristiwa stock split, investor juga harus jeli dalam menilai dan mengambil keputusan untuk memiliki saham dari perusahaan tertentu, apakah perusahaan tersebut memiliki prospek dan kinerja yang baik, apakah perusahaan memiliki nilai perusahaan yang baik dan memiliki reputasi yang baik dimata masyarakat umum khususnya para investor.

3. Investor juga harus mempertimbangkan kondisi pasar saham saat ingin melakukan trading, apakah pasar saham berada pada bearish market atau bullish market. Jika bearish market, maka memungkinkan kondisi 
tersebut tidak jauh berbeda dari penelitian yang dilakukan penulis. Dimana bearish market adalah kondisi dimana pasar saham mengalami tren penurunan, sedangkan bullish market adalah kondisi pasar saham mengalamin tren kenaikan.

Bagi perusahaan :

1. Perusahaan yang ingin melakukan kebijakan stock split harus lebih memperhatikan harga sahamnya terlebih dahulu, karena penentuan rasio yang tepat akan membuat harga saham berada pada rentang yang optimal yang membuat para investor tertarik untuk memiliki saham dari perusahaan tersebut.

2. Melihat kondisi pasar, perusahaan harus mempertimbangkan dengan matang apakah kebijakan stock split yang dilakukan saat kondisi pasar bullish market ataupun bearish market apakah tepat.

\section{DAFTAR PUSTAKA}

Ambarwati, S. D. A. (2008). Pengaruh Return Saham, Volume Perdagangan Saham Dan Varian Return Saham Terhadap Bid - Ask Spread Saham Pada Perusahaan Manufaktur Yang Tergabung Dalam Indeks LQ 45 Periode Tahun 2003 - 2005. Jurnal Siasat Bisnis. Vol 12, No. 1. April. Hal 27-38

Febrianti, Noerita (2014), Analisis Perbedaan Bid Ask Spread dan Volatilitas Saham Sebelum dan Sesudah Pengumuman Stock Split. Jurnal Ilmu Manajemen Vol. 2 No. 3. Fakultas Ekonomi, Universitas Negeri Surabaya.

Hendrawijaya Dj, Michael (2009), Analisis Perbandingan Harga Saham, Volume Perdagangan Saham, dan Abnormal Return Saham Sebelum dan Sesudah Pemecahan Saham (Studi pada perusahaan go public yang melakukan pemecahan saham antara tahun 2005 - 2008 di BEI ). Tesis. Semarang: Fakultas Manajemen, Universitas Diponegoro.

Istanti, Lulu Nurul (2009), Pengaruh Harga Saham, Trading Volume Activity, dan Risiko Saham Terhadap Bid Ask Spread (Studi Pada Perusahaan LQ 45 Di Bursa Efek Jakarta), Modernisasi, Vol 5, No.3, pp199-210.

Lestari, Slamet dan Eko Sudaryono (2008), Pengaruh Stock Split : Analisis Likuiditas Saham Pada Perusahaan Go Public Di Bursa Efek Indonesia Dengan Memperhatikan Pertumbuhan Dan Ukuran Perusahaan, Jurnal Bisnis Dan Akuntansi, Vol 10, No. 3, pp139-148.

Noor Rokhman, M.Taufiq (2009), Analisis Return, Abnormal Return, Aktivitas Volume Perdagangan dan Bid Ask Spread Saham Di Seputar Pengumuman Stock Split, Jurnal ISSN 1411-0199662 Vol. 12 No. 4

Sadikin, Ali (2011), Analisis Abnormal Return Saham dan Volume Perdagangan Saham Sebelum dan Sesudah Pemecahan Saham (Studi Pada Perusahaan Go Publik Di Bursa Efek Indonesia, Jurnal Manajemen dan Akuntansi, Vol. 12 No. $1, \quad$ pp 1-10.

Setyawan, Ignatius Roni (2010), Stock Split Dan Likuiditas Saham Di BEI : Pengujian Menggunakan Hipotesis Likuiditas, Jurnal Akuntansi Dan Keuangan Indonesia, Vol. 7, No. 2, pp124-138.

Sumiyana, 2007, "Noise atau Kedatangan Informasi: Sebuah Fenomena Spesifik Perilaku Harga Saham Dipasar Modal Indonesia", Jurnal Ekonomi dan Bisnis Indonesia, Vol.22, No.3,Hal 292-318, Universitas Gajah Mada,Yogyakarta. 
Harsono, Budi. (2013). Efektif Bermain Saham. Jakarta: PT. Elex Media Komputindo Kompas Gramedia.

Suryabrata, Sumadi (2010), Metodologi Penelitian, Rajawali Pers, Jakarta.

Tandelilin, Eduardus (2010), Portofolio dan Investasi Teori dan Aplikasi, Edisi Pertama, Kanisius, Yogyakarta.
https://id.wikipedia.org/wiki/Pasar_modal (diakses pada tanggal 19 April 2016)

http://www.idx.co.id// (diakses pada tanggal 20 April 2016)

http://www.idx.co.id/id-

id/beranda/perusahaantercatat/aktivitaspenc atatan.aspx (Diakses pada tanggal 20 April 2016)

Indonesian Capital Market Electronic Library (Pengambilan data pada tanggal 31 Oktober 2016) 
